\title{
Managing diabetes with inhaled insulin
}

Lucy D. Mastrandrea ${ }^{1}$

1 Department of Pediatrics, School of Medicine and Biomedical Sciences, University at Buffalo, Buffalo, New York

\section{Abstract}

The incidence of diabetes is increasing world-wide. Many individuals with diabetes require insulin to control their blood sugar and prevent both microvascular and macrovascular complications associated with this chronic disease. Current regimens involve delivery of subcutaneous insulin by injection or continuous insulin infusion. One area of research to advance diabetes care is aimed at developing alternate routes of insulin administration that will make daily management less invasive for patients. This review will focus on inhaled insulin, a novel formulation which takes advantage of drug delivery through the pulmonary system. The pharmacology, efficacy, and safety of inhaled insulin will be discussed. In addition, the status of inhaled insulin as a potential therapy for individuals with diabetes will be reviewed.

\section{Keywords}

Diabetes care; Glycemic control; Hemoglobin A1c; Inhalation; Insulin; Lung; Pulmonary; Type 1 diabetes; Type 2 diabetes 


\section{Introduction}

The International Diabetes Federation estimates that diabetes affects over 285 million individuals worldwide, with rates increasing particularly in developing nations [1]. The two major categories of diabetes are type 1 diabetes (T1D) and type 2 diabetes mellitus (T2D). T1D is caused by autoimmune destruction of the insulin-producing cells in the pancreas; individuals with this disease are completely dependent on insulin for survival. T2D, which occurs predominantly in obese individuals, develops when insulin production fails to compensate for peripheral tissue resistance to insulin $[2,3]$. Initially, individuals with T2D manage their disease with weight loss, exercise, and oral medications. As the disease progresses most will require insulin to prevent persistent hyperglycemia.

Since the discovery of insulin by Banting and Best in 1921 [4], the evolution of insulin therapy has focused primarily on modifying insulin preparations or the molecule itself to alter the pharmacodynamics and improve bio-availability. However, for many patients, subcutaneous insulin delivery is invasive and proves burdensome. A potential alternative to subcutaneous insulin is administration of insulin via inhalation. The development of inhaled insulin as a tool to manage diabetes will be reviewed.

\section{Goals in diabetes care}

Diabetes is the $7^{\text {th }}$ leading cause of death in the USA, and the cost of this disease exceeded $\$ 174$ billion in 2007 [5]. The American Diabetes Association publishes guidelines for diabetes care with the primary goal of optimizing metabolic control as measured by glycosylated hemoglobin (HbAlc) [6], a biochemical tool which correlates with mean blood sugar levels over the previous 2-3 months. The rationale for this goal is that numerous studies have demonstrated associations between hyperglycemia, elevated $\mathrm{HbAlc}$, and long-term complications of diabetes. Diabetes complications include both microvascular diseases - nephropathy, retinopathy, and neuropathy - and macrovascular diseases - atherosclerotic disease, myocardial infarctions, and stroke. Large prospective trials in cohorts of individuals with either T1D or T2D have shown that as diabetes control improves, the rate of microvascular disease decreases $[7,8]$. While these prospective trials did not show parallel findings with respect to macrovascular disease, follow-up studies in a group of patients with T1D who received intensified insulin therapy ( 3 or more injections per day) had a $42 \%$ decreased risk of a first cardiovascular event compared to subjects treated with conventional therapy [9]. Thus, the current clinical guidelines are to target as close to euglycemia as possible in every patient, while minimizing the risk of adverse effects, particularly hypoglycemia. In the non-diabetic state, the pancreas produces low amounts of insulin to regulate hepatic gluconeogenesis between meals (basal) while, in response to carbohydrate consumption, $\beta$-cells secrete insulin to control mealtime glucose excursions (bolus). Intensive therapy in patients with T1D aims to replicate this basal-bolus pattern by using insulin analogs with appropriate pharmacodynamic profiles or by continuous infusion with short-acting insulin analogs via insulin pump. Similar strategies are used by patients with $\mathrm{T} 2 \mathrm{D}$ who have persistent hyperglycemia in spite of optimized oral therapy with drugs that stimulate insulin production (secretagogues) or that improve insulin sensitivity (biguanides and thiazoladinediones).

In spite of the availability of intensified basal/bolus regimens, several barriers to optimizing glycemic control remain. First, subcutaneous delivery of insulin does not replace the hepatic effects of endogenous insulin secretion delivered directly into the portal circulation. Secondly, optimal glucose-lowering effect of short-acting insulin analogs is dependent on both the timing of dosing as well as careful attention to quantity and type of carbohydrates consumed. In addition, while intensification of insulin therapy leads to reductions in complications, there are corresponding increases in the risk of severe hypoglycemia [7]. Recurrent hypoglycemia is treatment limiting because it places patients at risk for 
seizures, unconsciousness, and potentially, death. Finally, many patients are resistant to take on the burden of intensified management. They may be fearful of injections or unprepared to learn the skills necessary to match carbohydrate intake with insulin administration.

It is estimated that $>60 \%$ of individuals with diabetes fail to reach therapeutic targets. With the above barriers in mind, efforts are underway to develop insulin regimens that will improve both overall glycemic control as well as acceptance by patients. The two formulations that have come farthest along the pipeline are Oral-lyn, insulin that is absorbed across the buccal mucosa, and inhaled insulin. Although only on the market for a brief period, the Exubera ${ }^{\circledR}$ inhaled insulin delivery device system was approved by the Food and Drug Association (FDA) and the European Medicines Agency (EMEA) for treatment of T1D and T2D.

\section{Delivering drugs through the pulmonary system}

In developing inhaled insulin, researchers took advantage of the fact that drugs have been delivered through the pulmonary system for a number of different diseases, including cystic fibrosis and asthma. For these conditions, the bronchiole tree or lung parenchyma is the target of drug action. For inhaled insulin to be effective, it must be absorbed across the large $\left(145 \mathrm{~m}^{2}\right)$, permeable, alveolar-capillary network of the lung to enter the bloodstream. In 1925, Gänsslen used nebulized insulin in subjects with T1D and reported that blood glucose levels decreased [10]. However, it was not until the development of devices capable of delivering drugs to the appropriate lung surface that the advancement of inhaled insulin could become a reality. In addition, research has focused on technologies to produce dry-powder formulations of insulin that meet the biophysical parameters facilitating deposition in the alveolar space and maximizing glucose-lowering activity [11,12].

There are a number of factors that influence the successful delivery of insulin to the deep lung space. First, insulin particle size should be between 1-3 $\mu \mathrm{M}$ to optimize deposition in the alveolar space [13]. This is achieved primarily by spray-drying liquid insulin combined with various excipients (such as liposomes, lactose, and porous polymers) aimed at minimizing clearance from the alveolar space and improving stability and absorption of the insulin. Secondly, the device must administer a consistent dose with each use in order to optimize glycemic control. This is dependent on timing of release of the insulin particles, particle velocity as well as the inspiratory effort of the user [14]. Finally, the devices and insulin formulations must be user-friendly, durable, and safe for patients.

\section{Inhaled insulin systems}

Inhaled insulin delivery systems differ with respect to size of the device, mechanism of insulin release (mechanical vs. electronic), insulin formulation (liquid vs. powder), and bioequivalence of the insulin formulation compared to subcutaneous insulin. Currently, there are at least two systems in continued development, with at least 3 active trials listed on www.clinicaltrials.gov [15].

- Exubera ${ }^{\circledR}$ is an inhaled insulin developed through a partnership with Nektar therapeutics, Pfizer, and Sanofi Adventis and approved as a pre-meal therapy for management of both T1D and T2D in the United States and Europe. Most of the original data related to the pharmacology of inhaled insulin was derived from studies testing Exubera ${ }^{\circledR}$. The mechanical device delivers a dry powder formulation of insulin from blister packets containing either $1 \mathrm{mg}$ or $3 \mathrm{mg}$ of regular insulin, which are bioequivalent to 3 units and 8 units of subcutaneous short-acting insulin, respectively. After just over one year of clinical use, Pfizer elected to withdraw Exubera ${ }^{\oplus}$ from the market, citing poor sales. In spite of these setbacks, Dance Pharmaceuticals, a company formed by individuals from Nektar, is resolved to redesign Exubera ${ }^{\circledR}$ technology in the hopes of bringing the drug to market again in the future [16]. 
- Afrezza ${ }^{\oplus}$ is an inhaled insulin product being developed by MannKind Corporation, and the system is the primary player in the field at this time. Using Technosphere ${ }^{\circ}$ technology, the device delivers a dry powder formulation of insulin that is rapidly absorbed into the circulation. The major advance is the replacement of the MedTone ${ }^{\oplus}$ Inhaler with the DreamBoat ${ }^{\circ}$ inhaler, a small breath-powered device that is designed to serve for a broad range of inhaled products [17]. Approval of Afrezza ${ }^{\circ}$ was recently denied by the FDA with requests for more data related to performance of the inhaler and risk of cardiovascular risks associated with Technosphere ${ }^{\circ}$ insulin. MannKind Corporation continues to pursue development of Afrezza ${ }^{\circ}$ for clinical use.

Other inhaled insulin systems have been developed and studied in patients but are no longer being investigated in clinical trials:

- The Alkermes' AIR system was developed in partnership with Eli Lilly. The device uses a breathactivated system to effectively deliver relative large, but porous, dry-powdered insulin particles (5$30 \mu \mathrm{m})$ to the deep lung space.

- The AERx iDMS ${ }^{\circ}$ system was being developed through a collaboration between Aradigm Corporation and Novo Nordisk. There are several unique features to this system. First, the device generates an aerosol from liquid insulin and then, using visual cues, signals the user to breathe at optimal speed and depth to ensure delivery of the insulin to the alveolar space. The therapeutic breath is followed by a "chaser breath" volume of $400 \mathrm{ml}$, making delivery more reproducible within and between subjects. Second, the liquid insulin is contained in blister packets each containing $1 \mathrm{AERx}^{\circ}$ unit of insulin. The device can deliver AERx $x^{\circ}$ units of insulin in 1 unit increments up to 10 units with each unit expected to equal one unit of insulin delivered subcutaneously. This provides increased flexibility for mealtime carbohydrate coverage, as well as the potential for fewer "puffs" of insulin at any given administration. Finally, the system can be downloaded, providing information related to delivered doses, frequency of use, and breathing patterns.

\section{Pharmacology of inhaled insulin}

The inhaled insulin systems that have been developed are designed to provide glycemic control at meal times (bolus) in patients with diabetes. The ideal inhaled insulin would have a glucose-lowering effect similar to that of endogenous meal-time insulin with rapid onset of glucose-lowering activity and duration of action over a period of 2-3 hours. This profile would control the rise in glucose while minimizing the risk of delayed hypoglycemia. The pharmacologic properties of inhaled insulin have been compared to those of subcutaneous insulin. Pharmacokinetics, as measured by serum levels of insulin following inhalation, describe how well the product is absorbed across the alveolar-capillary membrane to enter the bloodstream. The euglycemic glucose clamp technique is used to study the glucose lowering effect, pharmacodynamics, of inhaled insulin.

\section{Pharmacokinetic parameters of inhaled insulin}

Heinemann et al. studied the pharmacokinetics of inhaled insulin in 12 healthy, non-smoking males. Compared to injected regular insulin, serum insulin levels were reached more quickly ( $\mathrm{T}_{\max } 24$ vs. 106 min.), and the maximum insulin concentration $\left(\mathrm{C}_{\max }\right)$ was higher with inhaled insulin [18]. In addition, after insulin inhalation, the insulin exposure as measured by AUC was higher in the first 60 minutes of the clamp study, while the total AUC (360 min) was greater for injected insulin. By comparing the relative doses of insulin administered for each route, the authors concluded that the bioavailability of inhaled insulin is $7.8 \pm 3.5 \%$ of injected insulin. Studies performed in healthy non-smoking volunteers compared the pharmacokinetics of Exubera ${ }^{\circ}$ to regular insulin. This study confirmed that inhaled 
insulin is absorbed more rapidly than regular insulin; however, both the $\mathrm{C}_{\max }$ and cumulative insulin exposure were similar for the two drugs [19]. Rave et al. studied the AIR ${ }^{\circledast}$ inhaled insulin system in 18 healthy male and female subjects with normal pulmonary function to compare three different inhaled insulin doses to bioequivalent subcutaneous insulin lispro doses [20]. The $\mathrm{T}_{\max }$ was similar for all doses studied and did not differ between inhaled insulin and subcutaneous insulin, indicating that exposure to inhaled insulin mirrors that of the short-acting insulin analogs. As expected, the $\mathrm{C}_{\max }$ increased with increasing inhaled insulin dose. $\mathrm{C}_{\max }$ was lower for inhaled insulin compared to insulin lispro except at the highest dose tested, where it was similar. The AUC of equivalent doses was comparable for inhaled vs. subcutaneous insulin.

In summary, studies in patients without diabetes indicate that inhaled insulin displays initial pharmacokinetics $\left(\mathrm{T}_{\max }\right.$ and $\mathrm{C}_{\max }$ ) similar to short-acting analogs, while total exposure (AUC) is more like regular insulin.

\section{Glucodynamics of inhaled insulin}

The euglycemic glucose clamp provides a mechanism to measure the amount of glucose required to maintain euglycemia (and prevent hypoglycemia) following a given exposure to insulin. In agreement with the pharmacokinetic data, the time of maximal glucose infusion occurs earlier with inhaled insulin compared to subcutaneous regular insulin and the glucose infusion rates are higher in the first 60 minutes following drug exposure [18]. The duration of glucose-lowering effect for inhaled insulin is longer than insulin lispro and similar to regular insulin, while the total glucose exposure does not differ between insulin regimens $[19,20]$.

In order to study the glucose lowering effect of different inhaled insulin dose equivalents, healthy subjects inhaled AIR ${ }^{\oplus}$ insulin in single vs. divided doses. For example, subjects were treated with one $10 \mathrm{U}$ equivalent capsule and, on a separate occasion, one $6 \mathrm{U}$ equivalent capsule plus $2 \mathrm{U}$ equivalent capsules (total dose $=10 \mathrm{U}$ ). The total glucose infusion rates were comparable between these two regimens, indicating that doses can be interchanged with no loss in clinical efficacy [21].

Glucodynamics of inhaled insulin have also been studied in populations with diabetes. In individuals with T1D, the glucose lowering effect was achieved more quickly with inhaled insulin than with subcutaneous insulin [22]. In addition, total glucose exposure increased with escalating inhaled insulin dose. The intra-subject variability for glucose lowering effect was $\sim 34 \%$ indicating that inhalation technique is an important variable related to glycemic management. When individuals with T2D were treated with Technosphere ${ }^{\varpi}$ insulin, the time to maximal metabolic effect occurred sooner than with subcutaneous regular insulin. Although the glucose lowering activity for the inhaled and subcutaneous insulin doses were equal for the initial three hours of the clamp, the initial glucose exposure (0-2 hours) was higher for inhaled insulin, while the total glucose exposure was greater for regular insulin [23]. Interestingly, there was less intra-subject variability with inhaled insulin compared to subcutaneous insulin in this population. These results confirm that inhaled insulin would be effective as a prandial therapy with decreased risk for delayed hypoglycemia.

\section{Inhaled insulin and conditions that affect the pulmonary system}

The efficacy of inhaled insulin is dependent on an intact alveolar-capillary network as well as adequate delivery of the product to the site of absorption. Thus, environmental exposures and diseases which affect inhalation technique and insulin absorption will alter the glycemic action of the drug. 
Becker and colleagues studied the effect of smoking on the pharmacokinetics and pharmacodynamics of inhaled insulin. Compared to non-smokers, the maximal insulin concentration and total insulin exposure was higher in smokers following inhalation of Exubera ${ }^{\bullet}$ [24]. In addition, the peak insulin concentration was reached sooner. Wise et al. confirmed these findings demonstrating that the AUC-insulin increased by $58 \%$ and the maximal insulin concentration increased by $172 \%$ in smokers following insulin inhalation [25]. The effects of smoking on insulin absorption are not dependent on the inhaled insulin formulation, as similar pharmacokinetics are observed with dry powder and liquid aerosol insulin. In spite of the increased insulin exposure, the hypoglycemic effect as measured by glucose infusion rate was $50 \%$ lower in the smokers, suggesting a degree of insulin resistance in this population. Within one week of smoking cessation, the pharmacokinetics of inhaled insulin is equivalent to that of healthy non-smokers [24]. Finally, the effects of second-hand smoking on inhaled insulin pharmacology were studied in healthy non-smoking volunteers [26]. After sitting in a smokefilled room for $2 \mathrm{~h}$, the $\mathrm{T}_{\max }$ was increased compared to no smoke exposure (75 min. vs. $60 \mathrm{~min}$.), and the $\mathrm{C}_{\max }$ was decreased. In addition, in those exposed to cigarette smoke, the total insulin absorption (AUC) was less for all time periods tested (0-120, 0-240, and 0-360 min., respectively). Glucodynamics were not performed in this study; however, it could be inferred from the pharmokinetic data that the glucose-lowering effect of inhaled insulin would be impaired with exposure to second-hand smoke. When Exubera ${ }^{\circ}$ was approved by the FDA, it was not indicated for current smokers or those who had smoked within the previous 6 months. Post-marketing data demonstrated an increased risk of lung cancer in former smokers who were involved in clinical trials testing Exubera ${ }^{\circ}$. Thus, future approval of inhaled insulin is likely to be limited to non-smokers.

There are a number of acute and chronic comorbid pulmonary diseases that might influence the efficacy of inhaled insulin in individuals with diabetes. Upper and lower respiratory infections are relatively common, albeit short-lived conditions. In subjects without diabetes experiencing an upper respiratory illness, the pharmacokinetics and glucodynamics of inhaled insulin were not altered either during the acute or recovery phase [27], suggesting that inhaled insulin doses do not need to be adjusted during these illnesses. Asthma is a chronic restrictive lung disease characterized by airway hyper-reactivity, inflammation, and subsequent airway remodeling. Acute attacks of bronchospasm may be triggered by airway pollutants. For individuals who have both diabetes and asthma, it is essential to ascertain whether the glucose-lowering effect of inhaled insulin is altered during asthma exacerbations, and whether the inhalation event itself can trigger an asthma attack. Henry et al. studied the effect of AERx ${ }^{\circ}$ insulin inhalation on both the pharmacology and pulmonary function in a group of non-diabetic subjects with mild-moderate chronic asthma treated only with $\beta$-adrenergic agonist therapy [28]. Individuals with asthma absorbed less insulin compared to healthy controls, which correlated with decreased glucose-lowering effect of the drug. There was significant intra-subject variability in insulin absorption. This coupled with the lowered absorption would contribute to inconsistent insulin dosing and could lead to erratic glucose excursions. Woltz et al. performed a similar study with an asthmatic population stratified into mild and moderate disease [29]. Both groups had significantly lower insulin absorption compared to controls; however, only the group with moderate asthma showed a decreased glucodynamic response to inhaled insulin which was partially abrogated by pre-treating with a long-acting $\beta$-agonist. Inhaled insulin did not induce symptoms of airway hyper-reactivity, and there were no relevant changes in pulmonary function testing in either study. These findings suggest that, while inhaled insulin does not trigger bronchospasm, individuals with asthma who are treated with inhaled insulin must be counseled to monitor glucose levels closely. In addition, during acute asthma exacerbations, the option of transitioning back to subcutaneous insulin therapy may be warranted.

Individuals with the diagnosis of chronic obstructive pulmonary disease (COPD) suffer from either emphysema (restrictive disease) or chronic bronchitis (obstructive disease). COPD affects between 10-12\% of individuals with diabetes [30], and it is a risk factor for diabetes likely because of the inflammatory 
state and impact on exercise tolerance. Rave et al. studied the pharmacokinetics of $\mathrm{AIR}^{\circledast}$ inhaled insulin in a group of non-smoking individuals with COPD, stratifying them into a chronic bronchitis group and an emphysema group [31]. Compared to controls, serum insulin levels following inhalation were lower in both groups. In fact, for the chronic bronchitis cohort, the $\mathrm{C}_{\max }$ and total insulin exposure were $59.3 \%$ and $55.7 \%$ of healthy controls. The glucose lowering effect of inhaled insulin was significantly lower in both groups compared to controls, with a high degree of intra-subject variability. In addition to having a negative impact on inhaled insulin pharmacology, subjects with chronic bronchitis had a consistent decline in forced expiratory volume in 1 second $\left(\mathrm{FEV}_{1}\right)$ following treatment. Recently, a trial using Technosphere failed to demonstrate differences in insulin absorption in 19 subjects with mild to moderate COPD [32]. Whether these findings are related to the study population or to the inhaled insulin formulation will need to be addressed in larger studies. However, given that the most common etiology of COPD is tobacco use, this population may be excluded from using inhaled insulin based on smoking history alone.

\section{Clinical use of inhaled insulin}

The efficacy and safety of inhaled insulin has been studied in clinical trials involving subjects with both $\mathrm{T} 1$ and T2 diabetes. In addition, the use of inhaled insulin in special populations - pediatrics (T1D) and adults over the age of 65 (T2D) - has been tested.

\section{Type 1 diabetes}

Individuals with T1D are reliant on insulin replacement for survival, and most patients require multiple daily injection insulin therapy in order to optimize diabetes control. While continuous subcutaneous insulin infusion therapy provides flexibility in terms of dosing and does not require daily injections, not all individuals are candidates for the insulin pump. Inhaled insulin would provide prandial mealtime coverage when combined with basal insulin, thereby limiting the number of injections.

Several different inhaled insulin systems have been used in randomized controlled trials testing the efficacy of inhaled insulin. Quattrin et al. performed a randomized parallel-group open-label study in 334 subjects with T1D, including 62 pediatric patients (age 12-18 years). When mealtime Exubera ${ }^{\circledR}$ plus Ultralente was compared to regular insulin plus NPH, there was no difference in metabolic control between the two groups, although fasting and 2-hour post-prandial glucose levels were lower in those receiving inhaled insulin [33]. These observations may not be attributable to inhaled insulin alone since the basal insulin therapy also differed between the groups. With the development of fast-acting insulin analogs, inhaled insulin could be compared to drugs with similar glucodynamics. Comulada and colleagues tested pre-meal AIR ${ }^{\circledast}$ inhaled insulin in combination with insulin glargine compared to insulin lispro/glargine. While HbAlc improved more in the cohort treated with lispro/glargine, a similar number of patients achieved the target $\mathrm{HbAlc}$ of $<7 \%$ in each group [34]. Longer term studies have also examined the ability of inhaled insulin to offer durable effects on glycemic control. In a 2-year study comparing AIR ${ }^{\circledR}$ insulin to either subcutaneous regular or lispro insulin in combination glargine, inhaled insulin was less efficacious in lowering HbA1c [35]. Reductions in HbA1c were comparable in individuals treated for one year with glargine plus either Technosphere ${ }^{\circledast}$ insulin or rapid-acting insulin analog [36]. Fasting plasma glucose was lower in those receiving Technosphere ${ }^{\star}$ These results suggest that inhaled insulin is, at best, non-inferior to subcutaneous insulin in controlling blood glucose levels in those with T1D.

\section{Type 2 diabetes}

After initiation of lifestyle intervention strategies, the algorithm for escalating pharmacotherapy in individuals with T2D with suboptimal glycemic control includes introduction of oral metformin therapy [37]. If glucose levels remain elevated, second tier therapies include oral hypoglycemic agents, thia- 
zolidendiones, and basal insulin. Over time, many individuals will require prandial insulin coverage to control mealtime glucose excursions. Inhaled insulin has been tested in the T2D population in subjects naïve to insulin and those treated with insulin.

When glycemic control continues to be suboptimal on dual oral agent therapy, most clinicians choose to introduce basal insulin therapy. Hompesh et al. tested the hypothesis that addition of prandial inhaled insulin ( 3 doses per day) would lower glucose exposures to a greater degree than insulin glargine (1 dose per day) in a T2D cohort poorly controlled on oral agents [38]. Using a continuous glucose monitoring system, they demonstrated that the addition of Exubera ${ }^{\circ}$ lowered 24 hour glucose levels, particularly after meals, more effectively than basal insulin. In a similar population, the addition of either prandial AIR inhaled insulin or insulin lispro to oral therapy resulted in comparable reductions in HbAlc after 6 months of therapy [39]. When Exubera ${ }^{\circledR}$ was substituted for or added to dual oral therapy in a cohort of T2D patients with $\mathrm{HbAlc}>8 \%$, the change in HbAlc from baseline was significantly lower for those subjects receiving inhaled insulin vs. those receiving oral therapy alone [40]. While the combination of oral therapy and Exubera ${ }^{\circ}$ led to the highest percentage of subjects achieving $\mathrm{HbAlc}$ $<7 \%(32 \%)$, more subjects reached target HbAlc with inhaled insulin alone compared to dual oral therapy ( $16.7 \%$ vs. $1 \%)$. This suggests that inhaled insulin alone may represent a valid treatment option in this population. A weakness of the above study is the lack of a placebo-controlled arm. It is possible that the novelty of using the inhaled insulin device biased the results in favor of improved diabetes control in those receiving Exubera ${ }^{\circ}$. To control for this pitfall, MannKind developed a Technosphere ${ }^{\circ}$ placebo device. In insulin-naïve patients with T2D treated with at least one oral agent, the addition of inhaled Technosphere ${ }^{\circ}$ insulin led to a significantly greater reduction in HbAlc from baseline $(-0.72$ vs. $-0.30 \%$ ) compared to placebo Technosphere ${ }^{\circ}$ powder [41].

The availability of inhaled insulin to cover meal-time glucose excursions has the potential to decrease the number of insulin injections for individuals with T2D on intensive insulin therapy. Hollander et al. studied the effect of Exubera on glycemic control in a cohort of T2D subjects treated with at least 2 insulin injections per day but on no oral medications [42]. Subjects were randomized to receive twice daily dosing of regular + NPH insulin or premeal Exubera + Ultralente insulin before bedtime. The difference between the mean change from baseline $\mathrm{HbAlc}$ for the groups was not statistically different. However, in the inhaled insulin group, more subjects achieved HbAlc $<7 \%$, and the fasting plasma glucose was significantly lower. In another study, individuals with T2D treated with oral agents plus glargine were randomized to one of three arms - continuation of glargine alone, initiation of AIR ${ }^{\circ}$ prandial insulin alone, or addition of $\mathrm{AIR}^{\circledast}$ prandial insulin to glargine [43]. A forced titration algorithm was used to intensify glycemic control in those continuing on glargine. As might be predicted, post-prandial glucose excursions were significantly lower in subjects randomized to inhaled insulin. This translated to a significant decrease in HbAlc from baseline in the two arms receiving inhaled insulin compared to the glargine alone group; there was no difference between the group randomized to inhaled + glargine vs. inhaled alone. These findings demonstrate that addition of mealtime inhaled insulin has beneficial effects on glucose control in the T2D population. Studies comparing inhaled insulin to short-acting insulin analogs in subjects already using prandial insulin have not been reported. However, based on experiences in insulin-naïve patients [39], it is likely that inhaled insulin would be non-inferior to subcutaneous insulin with respect to overall glycemic control. As a result, decisions to initiate or transition to inhaled insulin would be dependent on patient preference and treatment risks.

\section{Safety of inhaled insulin}

Safety and adverse events have been studied in populations exposed to inhaled insulin. The most common immediate treatment-related complaint was cough which generally decreased over time and was 
rarely treatment-limiting. Other important safety considerations are related to insulin itself as well as effects of insulin inhalation on the pulmonary system. These include hypoglycemia, weight gain, and changes in lung function.

Intensification of insulin therapy places individuals with diabetes at risk for hypoglycemia. In fact, the Diabetes Control and Complications Trial demonstrated that as glycemic control improves, the rates of severe hypoglycemic events increase [7]. Extensions studies during which some subjects transitioned from regular insulin to short-acting insulin analogs showed further reductions in HbAlc without corresponding increases in hypoglycemia rates [44]. In spite of the fact that the pharmacokinetics of inhaled insulin compares more favorably with short-acting insulin analogs, hypoglycemia is always a concern, particularly in insulin-naïve subjects. In studies including individuals with T1D, reports of hypoglycemia were similar for inhaled insulin and subcutaneous therapy [33-35]. Skyler et al. reported a higher rate of severe hypoglycemic events in subjects treated with inhaled insulin compared to regular insulin (6.5 vs. 2.3 episodes/100 patient months) [45]. However, the increased rate of hypoglycemia in this study may have been attributed to the fact that the basal insulin used in the study was twice daily $\mathrm{NPH}$, while other studies combined inhaled insulin with glargine or Ultralente. In a study comparing Technosphere ${ }^{\circledast}$ insulin to Technosphere ${ }^{\circledast}$ placebo in insulin-naïve T2 subjects, there was no increase in hypoglycemic events/month in those receiving inhaled insulin [41]. Hypoglycemia rates were higher in individuals with T2D treated with inhaled insulin either alone or in combination with two oral agents compared to those treated with oral agents alone [40]. In a study of subjects with poorly controlled T2D on two oral agents, the incidence of hypoglycemia was comparable between inhaled AIR ${ }^{\varpi}$ insulin and lispro insulin [39].

Another important aspect of optimizing diabetes care is weight control. Obesity is the primary contributor to the development of insulin resistance that is the precursor of T2D, and weight loss can reverse many of the metabolic defects associated with the disease. Even in T1D diabetes, excessive weight gain creates an insulin resistant state, necessitating escalation of insulin doses to maintain glycemic control. When insulin therapy is started or intensified, many individuals gain weight, both because of the anabolic effects of the hormone and in response to hypoglycemia (actual or perceived). In subjects with T1D, weight change was either the same [46] or slightly decreased [33-35] in subjects treated with inhaled insulin compared to subcutaneous insulin. In those with T2D, insulin naïve patients treated with inhaled insulin gained more weight than those continuing on oral agents [40]. However, in studies comparing prandial inhaled insulin to short-acting subcutaneous insulin, there was either no change or less weight gain in those randomized to inhaled insulin $[39,47,48]$.

The unique safety issue of inhaled insulin compared to other insulin formulations is related to potential effects on lung function. In spite of significantly lower affinity, insulin does have growth-promoting effects through the insulin growth factor-1 receptor. Since larger quantities of insulin must be inhaled to achieve a bioequivalent effect on glucose control, the hypothetical risk of overgrowth and remodeling to the alveolar-capillary network and epithelial lining of the bronchiole tree are higher. In addition, there is the concern about the long-term effects of inhalation of particulate matter into the airways. As a result, many clinical studies performed pulmonary function testing to assess the effects of inhaled insulin on both lung volumes and diffusion capacity. Short term (12 weeks) studies with inhaled insulin in T2D showed no change from baseline in either $\mathrm{FEV}_{1}$ or diffusion capacity for carbon monoxide $\left(\mathrm{DL}_{\mathrm{CO}}\right)$ [40,49]. Longer term studies (6 months) in subjects with T1D showed small but equivalent changes in $\mathrm{FEV}_{1}$ and total lung capacity in all subjects, while those who received inhaled insulin had a small but significant decrease in $\mathrm{DL}_{\mathrm{CO}}$ compared to those treated with subcutaneous insulin $[33,46]$. The clinical significance of these changes in diffusion capacity is unclear. Extension trials (1-4 years) did not reveal any delayed effects of inhaled insulin on lung volumes, and the changes in $\mathrm{DL}_{\mathrm{CO}}$ did not worsen over longer treatment periods [39,43,50,51]. Comulada et al. showed that following discontinuation of $\mathrm{AIR}^{\otimes}$ inhaled insulin, $\mathrm{DL}_{\mathrm{CO}}$ remained significantly lower in subjects treated with inhaled 
insulin compared to the group randomized to lispro insulin [34]. However, in a study which tested the effect of initiation, discontinuation, and reinitiation of Exubera ${ }^{\bowtie}$ over a three year period of time, Skyler et al. showed that changes in $\mathrm{FEV}_{1}$ and $\mathrm{DL}_{\mathrm{CO}}$ occurred within three months of initiation of inhaled insulin, resolved within one month of discontinuing inhaled insulin, and reoccurred with resumption of inhaled insulin [52]. There was no evidence of progressive decline in lung function, and repeated treatment did not exacerbate differences between the groups. These findings suggest that lung function will not deteriorate with prolonged inhaled insulin use. However, it is likely that regulatory agencies will recommend that pulmonary function testing be performed prior to initiating inhaled insulin products. In addition, regular testing of lung function will be part of surveillance care in those treated with inhaled insulin. Thresholds for baseline function and decline in function will trigger discontinuation of therapy. Finally, history of tobacco use may be a contraindication to inhaled insulin [53].

\section{Inhaled insulin: patient satisfaction and adherence}

As discussed above, inhaled insulin has proven to be non-inferior to subcutaneous insulin in achieving the goal of diabetes care: improving glycemic control. As yet, there are no long-term studies to demonstrate that inhaled insulin has a favorable impact on chronic complications related to diabetes care, including progression to cardiovascular or renal disease. The FDA rejected MannKind's application for approval of Afrezza ${ }^{\circledR}$ requesting further data related to the cardiovascular safety of the drug. Recently, Bilheimer et al. reviewed adverse events in over 4400 patients treated with Afrezza in clinical trials and reported that there is no increased risk of cardiovascular events in any group receiving the inhaled insulin [54].

For inhaled insulin to be successful in the diabetes care arena, the product must offer an additional advantage in patient care. One of the perceived benefits of inhaled insulin is that patients will find the delivery system less cumbersome and anxiety-provoking than injection devices. As a result, patient satisfaction, quality of life, and adherence would improve and translate to positive effects on glycemic control. When over 1000 adults with self-reported T2D were surveyed regarding the perceived benefits of inhaled insulin, those who were not currently treated with insulin responded that the availability of an inhaled insulin product would increase the likelihood that they would agree to add insulin to their medical regimen [55]. In a 1 year extension study, individuals with diabetes randomized to either Exubera ${ }^{\bowtie}$ or subcutaneous insulin for 12 weeks were allowed to choose their treatment regimen [56]. Of those initially randomized to inhaled insulin, $85 \%$ elected to continue therapy, and $75 \%$ of those initially on subcutaneous therapy transitioned to inhaled insulin. Patient satisfaction, including ease of use and social comfort, improved significantly from baseline for subjects continuing or switching to inhaled insulin compared to subjects treated with subcutaneous insulin. Importantly, these improvements in patient satisfaction were accompanied by sustained decreases in mean HbAlc.

The definition of adherence is whether a patient follows the medical regimen at the dose and frequency prescribed by the physician. Adherence rates strongly correlate with disease control; however, the likelihood of adherence to medical therapy in chronic disease decreases significantly as the medical regimen becomes more complicated [57]. Mechanisms for assessing adherence in diabetes include patient report, measurement of diabetes control, and pharmacy fill rates, all of which are fraught with inaccuracies. The AERx ${ }^{\circledast}$ system records the number of delivered insulin doses and provides information about the adequacy of breathing techniques performed by the patient. Thus, it provides a unique opportunity to assess adherence to insulin therapy. When individuals with T2D used AERx ${ }^{\circledR}$ as preprandial therapy, the adherence rate was 95\%. In addition, the sustained improvement in glycemic control identified in long-term extension trials with inhaled insulin strongly support patient acceptance and adherence to the therapy. 


\section{Future of inhaled insulin}

Since Pfizer withdrew Exubera ${ }^{\circ}$ from the market due to poor acceptance, only MannKind is actively developing an inhaled insulin product for clinical use. While Pfizer reported increased rates of lung cancer in former smokers who received Exubera ${ }^{\circ}$ during preclinical trials, Aradigm and NovoNordisk did not identify any occurrences of lung cancer in subjects treated with AERx ${ }^{\circ}$ inhaled insulin [58]. Hurdles that must be overcome in the continued development and launch of inhaled insulin products relate specifically to the cost/benefit ratio. The annual cost of inhaled insulin is estimated to be at least 2-4 fold higher than bioequivalent amounts of subcutaneous insulin depending on the population served [59]. Prescription benefit plans will need to determine whether cost savings that arise from improved patient adherence, including prevention of chronic diabetes complications, will justify the increased cost. Inhaled insulin also faces competition from other alternative methods of insulin delivery as well as advances in subcutaneous insulin delivery systems such as combined insulin pump/ continuous glucose monitoring systems. The near future will determine whether inhaled insulin will be available as an alternative in the treatment of diabetes.

Questions for further research

If inhaled insulin is approved for clinical use by regulatory agencies, many questions will be addressed in post-marketing studies. The first is whether a greater proportion of individuals with diabetes meet glycemic targets with inhaled insulin. In addition, the potential role that inhaled insulin will play in mitigating chronic diabetes comorbidities can be assessed with respect to its effects on glycemic control. Secondly, the long-term effects of inhaled insulin on the lung must be addressed, particularly in the T1D population where inhaled insulin therapy may be introduced at an earlier age. Cost-benefit analyses must continue to address how use and acceptance of inhaled insulin is influenced by the changing healthcare environment as well as advances in insulin production, bioavailability, and delivery. Finally, future research in this field may lead to the development of longacting inhaled insulin analogs to replace subcutaneous basal therapy thereby providing a needlefree insulin administration system.

The review in brief

Clinical question Diabetes is a chronic disease characterized by hyperglycemia. While significant advances have been made in the field of diabetology in terms of understanding the pathophysiology of the disease, associated comorbidities, and therapeutic developments, long-term diabetes management is still based predominantly on subcutaneous insulin therapy. This review will focus on the journey to develop an alternate route of insulin delivery, namely, inhaled insulin.

Type of review Narrative

Literature search PubMed, with the following keywords: Diabetes care; Glycemic control; Hemoglobin A1c; Inhalation; Insulin; Lung; Pulmonary; Type 1 diabetes; Type 2 diabetes

Conclusions Inhaled insulin may serve as an alternative to subcutaneous insulin for management of diabetes, facilitating adherence while maintaining optimal glycemic control.

Limitations The cost of inhaled insulin, coupled with questions about long-term safety, remain potential barriers to acceptance and widespread use of inhaled insulin in patients with diabetes. 


\section{References}

1. http://www.idf.org/diabetesatlas/economic-impacts-diabetes (last accessed January 2012)

2. Ginsberg H, Kimmerling G, Olefsky J, Reaven G. Demonstration of insulin resistance in untreated adult onset diabetic subjects with fasting hyperglycemia. J Clin Invest 1975; 55: 454-61

3. Porte D, Kahn S. The key role of islet dysfunction in type 2 diabetes mellitus. Clin Invest Med 1995; 84:4-8

4. Bliss M. The Discovery of Insulin. University of Chicago Press. 1982

5. CDC: National Diabetes Fact Sheet. United States. 2007. Available at:http://www.cdcgov/diabetes/ pubs/factsheet07htm (last accessed January 2012)

6. American Diabetes Association, Standards of Medical Care in Diabetes-2011. Diabetes Care 2011; 34: S11-S61

7. The Diabetes Control and Complications Trial Research Group. The effect of intensive treatment of diabetes on the development and progression of long-term complications in insulin-dependent diabetes mellitus. N Engl J Med 1993; 329: 977-86

8. UK Prospective Diabetes Study (UKPDS) Group. Intensive blood-glucose control with sulphonylureas or insulin compared with conventional treatment and risk of complications in patients with type 2 diabetes (UKPDS 33). Lancet 1998; 352: 854-65

9. Nathan DM, Cleary PA, Backlund JY, Genuth SM, Lachin JM, Orchard JM, et al; Diabetes Control and Complications Trial/Epidemiology of Diabetes Interventions and Complications (DCCT/ EDIC) study research group. Intensive diabetes treatment and cardiovascular disease in patients with type 1 diabetes. $N$ Engl J Med 2005; 353: 2643-53

10. Gänsslen M. Über inhalation von insulin. Klin Wochenschr 1925; 4: 71

11. Labiris NR, Dolovich MB. Pulmonary drug delivery. Part II: The role of inhalant delivery devices. Drug formulations in therapeutic effectiveness of aerosolized medications. J Clin Pharmacol 2003; 56: $600-12$

12. Klingler C, Müller BW, Steckel H. Insulin-micro- and nanoparticles for pulmonary delivery. Int $J$ Pharm 2009; 377: 173-9

13. Edwards D, Dunbar C. Bioengineering of therapeutic aerosols. Annu Rev Biomed Eng 2002; 4: 93-107

14. Byron PR. Prediction of drug residence times in regions of the human respiratory tract following aerosol inhalation. J Pharm Sci 1986; 75: 433-8

15. www.clinicaltrials.gov/ct2/results?term=inhaled+insulin (last accessed January 2012)

16. http://www.diabetesmine.com/2011/01/dance-pharmaceuticals-gives-inhaled-insulin-a-do-overexubera-3-0.html (last accessed January 2012)

17. http://www.mannkindcorp.com/our-technology-inhalers.htm (last accessed January 2012)

18. Heinemann L, Traut T, Heise T. Time-action profile of inhaled insulin. Diabet Med 1997; 14: 63-72

19. Rave K, Bott S, Heinemann L, Sha S, Becker RHA, Willavize SA, et al. Time-action profile of inhaled insulin in comparison with subcutaneously injected insulin lispro and regular human insulin. Diabetes Care 2005; 28: 1077-82

20. Rave K, Nosek L, de la Peña A, Seger M, Ernest C, Heinemann L, et al. Dose response of inhaled dry-powder insulin and dose equivalence to subcutaneous insulin lispro. Diabetes Care 2005; 28: 2400-5

21. de la Peña A, Seger M, Rave K, Heinemann L, Silverman B, Muchmore DB. AIR insulin capsules of different dose strengths may be combined to yield equivalent pharmacokinetics and glucodynamics. Diabetes Technol Ther 2009; 11: S75-S79

22. Brunner GA, Balent B, Ellmerer M, Schaupp L, Siebenhofer A, Jendle JH, et al. Dose-response relation of liquid aerosol inhaled insulin in Type 1 diabetic patients. Diabetologia 2001; 44: 305-8 
23. Rave K, Heise T, Heinemann L, Boss AH. Inhaled technosphere insulin in comparison to subcutaneous regular human insulin: time action profile and variability in subjects with type 2 diabetes. $J$ Diabetes Sci Technol 2008; 2: 205-12

24. Becker RH, Sha S, Frick AD, Fountaine RJ. The effect of smoking cessation and subsequent resumption on absorption of inhaled insulin. Diabetes Care 2006; 29: 277-82

25. Wise S, Chien J, Yeo K, Richardson C. Smoking enhances absorption of insulin but reduces glucodynamic effects in individuals using the Lilly-Dura inhaled insulin system. Diabet Med 2006; 23: 510-5

26. Fountaine R, Milton A, Checchio T, Wei G, Stolar M, Teeter J, et al. Acute passive cigarette smoke exposure and inhaled human insulin (Exubera) pharmacokinetics. Br J Clin Pharmacol 2008; 65: 864-70

27. McElduff A, Mather LE, Kam PC, Clauson P. Influence of acute upper respiratory tract infection on the absorption of inhaled insulin using the AERx insulin diabetes management system. $\mathrm{Br} J$ Clin Pharmacol 2005; 59: 546-51

28. Henry RR, Mudalier S, Howland WC, Chu N, Kim D, An B, et al. Inhaled insulin using the AERx insulin diabetes management system in healthy and asthmatic subjects. Diabetes Care 2003; 26: 764-9

29. Wolzt M, de la Peña A, Berclaz PY, Tibaldi FS, Gates JR, Muchmore DB. AIR inhaled insulin versus subcutaneous insulin: pharmacokinetics, glucodynamics and pulmonary function in asthma. Diabetes Care 2008; 31: 735-40

30. Woodward L, Urech T, Landrum C, Wang D, Petersen L. Impact of comorbidity type on measures of quality for diabetes care. Medical Care 2011; 49: 605-10

31. Rave K, de la Peña A, Tibaldi FS, Zhang L, Silverman B, Hausmann M, et al. AIR inhaled insulin in subjects with chronic obstructive pulmonary disease. Diabetes Care 2007; 30: 1777-82

32. Potocka E, Amin N, Cassidy J, Schwartz SL, Gray M, Richardson PC, et al. Insulin pharmacokinetics following dosing with Technosphere insulin in subjects with chronic obstructive pulmonary disease. Curr Med Res Opin 2010; 26: 2347-53

33. Quattrin T, Bélanger A, Bohannon NJ, Schwartz SL. Efficacy and safety of inhaled insulin (Exubera) compared with subcutaneous insulin therapy in patients with type 1 diabetes. Diabetes Care 2004; 27: 2622-7

34. Comulada A, Renard E, Nakano M, Rais N, Mao X, Webb DM, et al. Efficacy and saftety of AIR inhaled insulin compared to insulin lispro in patients with Type 1 diabetes mellitus in a 6-month, randomized, noninferiority trial. Diabetes Technol Ther 2009; 11: S17-S25

35. Garg SK, Mathieu C, Rais N, Gao H, Tobian JA, Gates JR, et al. Two-year efficacy and safety of AIR inhaled insulin in patients with type 1 diabetes: An open-label randomized controlled trial. Diabetes Technol Ther 2009; 11: S5-S16

36. Bergenstal RM, Kapsner PL, Rendell MS, Boss AH, Howard CP, Chang PC, et al. Comparative efficacy and safety of AFRESA and a rapid-acting analog both given with glargine in subjects with T1DM in a 52-week study. Diabetes 2009: A479

37. Nathan D, Buse J, Davidson M, Ferrannini E, Holman R, Sherwin R, et al. Medical management of hyperglycemica in type 2 diabetes: a consensus algorithm for the initiation and adjustment of therapy. Diabetes Care 2009; 32: 193-203

38. Hompesch M, Kollmeier A, Rave K, Heinemann L, Mitnick M, Davies S, et al. Glycemic exposure is affected favorably by inhaled human insulin (Exubera) as compared with subcutaneous insulin glargine (Lantus) in patients with type 2 diabetes. Diabetes Technol Ther 2009; 11: 307-13

39. Gross JL, Nakano M, Colon-Vega G, Ortiz-Carasquillo R, Ferguson JA, Althouse S, et al. Initiation of prandial insulin therapy with AIR inhaled insulin or insulin lispro in patients with type 2 diabetes: a randomized noninferiority trial. Diabetes Technol Ther 2009; 11: S27-S34 
40. Rosenstock J, Zinman B, Murphy LJ, Clement SC, Moore P, Bowering CK, et al. Inhaled insulin improves glycemic control when substituted for or added to oral combination therapy in type 2 diabetes: a randomized, controlled trial. Ann Intern Med 2005; 143: 549-58

41. Rosenstock J, Bergenstal R, DeFronzo RA, Hirsch IB, Klonoff D, Boss AH, et al. Efficacy and safety of Technosphere inhaled insulin compared with Technosphere powder placebo in insulin-naive type 2 diabetes suboptimally controlled with oral agents. Diabetes Care 2008; 31: 2177-82

42. Hollander PA, Blonde L, Rowe R, Mehta AD, Milburn JL, Hershon KS, et al. Efficacy and safety of inhaled insulin (Exubera) compared with subcutaneous insulin therapy in patients with type 2 diabetes. Diabetes Care 2004; 27: 2356-62

43. Rosenstock J, Eliaschewitz F, Heilmann C, Muchmore DB, Hayes R, Belin R. Comparison of prandial AIR inhaled insulin alone to intensified insulin glargine alone and to AIR insulin plus intensified insulin glargine in patients with type 2 diabetes previously treated with once-daily insulin glargine. Diabetes Technol Ther 2009; 11: S63-S73

44. Chase H, Lockspeiser T, Peery B, Shepherd M, MacKenzie T, Anderson J, et al. The impact of the diabetes control and complication trial and humalog insulin on glycohemoglobin levels and severe hypoglycemia in type 1 diabetes. Diabetes Care 2001; 24: 430-4

45. Skyler JS, Weinstock RS, Raskin P, Yale JF, Barrett E, Gerich JE, et al. Use of inhaled insulin in a basal/bolus insulin regimen in type 1 diabetic subjects. Diabetes Care 2005; 28: 1630-5

46. Skyler JS, Cefalu WT, Kourides IA, Landschulz WH, Balagtas CC, Cheng S-L, et al. Efficacy of inhaled human insulin in type 1 diabetes mellitus: a randomised proof-of-concept study. Lancet 2001; 357: 331-5

47. Cefalu WT, Skyler JS, Kourides IA, Landschulz WH, Balagtas CC, Cheng S-L, et al. Inhaled human insulin treatment in patients with type 2 diabetes mellitus. Ann Intern Med 2001; 134: 203-7

48. Rosenstock J, Lorber D, Gnudi L, Howard CP, Bilheimer D, Chang PC, et al. Prandial inhaled insulin plus basal insulin glargine versus twice daily biaspart insulin for type 2 diabetes: a multicentre randomised trial. Lancet 2010; 375: 2244-53

49. Hermansen K, Rönnemaa T, Petersen AH, Bellaire S, Adamson U. Intensive therapy with inhaled insulin via the AERx insulin diabetes management system. Diabetes Care 2004; 27: 162-7

50. Skyler JS. Sustained long-term efficacy and safety of inhaled insulin during 4 years of continuous therapy. Diabetes. 2004; 53: A115

51. Skyler JS, Jovanovic L, Klioze S, Reis J, Duggan W. Two-year safety and efficacy of inhaled human insulin (Exubera) in adult patients with type 1 diabetes. Diabetes Care 2007; 30: 579-85

52. Skyler JS, Hollander PA, Jovanovic L, Klioze S, Krasner A, Riese RJ, et al. Safety and efficacy of inhaled human insulin (Exubera ${ }^{\circ}$ ) during discontinuation and readministration of therapy in adults with type 1 diabetes: a 3-year randomized controlled trial. Diabetes Res Clin Pract 2008; 82: 238-46

53. Kling J. Inhaled insulin's last gasp? Nat Biotech 2008; 26: 479-80

54. Bilheimer D, Ren H, Boss AH. Analysis of cardiovascular adverse events in patients with type 1 or type 2 diabetes enrolled in selected therapeutic trials in the phase $2 / 3$ Technosphere insulin development program [abstract]. Diabetes 2011; 60: A933

55. Peyrot M, Rubin R. Perceived medication benefits and their association with interest in using inhaled insulin in type 2 diabetes: a model of patients' cognitive framework. Patient Prefer Adherence 2011; 5: 255-65

56. Rosenstock J, Capelleri JC, Bolinder B, Gerber RA. Patient satisfaction and glycemic control after 1 year with inhaled insulin (Exubera) in patients with type 1 or type 2 diabetes. Diabetes Care 2004; 27: $1318-23$

57. Claxton AJ, Cramer J, Pierce C. A systematic review of the associations between dose regimens and medication compliance. Clin Ther 2001; 23: 1296-310 
58. http://www.drugs.com/clinical_trials/aradigm-announces-data-showing-no-occurrence-prima ry-lung-cancer-patients-treated-aerx-insulin-4128.htm] (last accessed January 2012)

59. Black C, Cummins E, Royle P, Philip S, Waugh N. The clinical effectiveness and cost-effectiveness of inhaled insulin in diabetes mellitus: a systematic review and economic evaluation. Health Technol Assess 2007; 11: 33 